\title{
EDUCAR PARA O MUNDO. EXTENSÃO EM \\ RELAÇÕES INTERNACIONAIS: DIREITOS HuMANOS E IMIGRAÇÃo EM SÃo PAULO
}

Ivy Mayumi de Moraes*

Resumo: O projeto Educar Para o Mundo propõe construir uma nova práxis de extensão universitária na área de relações internacionais, calcada na pedagogia freiriana. Por meio de uma metodologia dialógica de ação sobre a realidade que queremos transformar fazendo com que as pessoas se tornem sujeitos da sua própria transformação, práticas alternativas de difusão e ensino de direitos humanos - com foco na promoção dos direitos de imigrantes latino-americanos - foram inseridas em uma escola pública na cidade de São Paulo e na comunidade que a circunscreve. Assim, objetiva-se discorrer acerca das principais atividades desenvolvidas pelo projeto, para, em seguida, analisá-lo criticamente, buscando contribuir para a construção do fazer extensionista.

Palavras-chave: Extensão comunicativa; Imigração; Direitos Humanos.

Abstract: The project "Educar para o Mundo" proposes to build a new praxis of University Extension in the area of international relations, based on Freire's pedagogy. Through a dialogical methodology of social intervention for the transformation of reality and seeking to get people to become subjects of this process, alternative practices of human rights diffusion and education - with a focus on promoting the rights of Latin Americans immigrants - were included in a public school in the city of São Paulo and the circumscribed community. Thus, the objective is to talk about the main activities developed by the project, and then analyze it critically, seeking to contribute to the construction of the extension practice.

Keywords: Communicative extension; Immigration; Human Right.

* Graduanda do curso de Bacharelado em Relações Internacionais pelo Instituto de Relações Internacionais da Universidade de São Paulo (USP). E-mail: ivydemoraes@usp.br. A escolha do nome da autora ocorreu por necessidade editorial. Este artigo é de autoria do coletivo "Educar para o Mundo". 
|142|

Educar para o Mundo...

\section{Introdução}

O conceito de Extensão Universitária é uma expressão em disputa acerca da maneira como deve se estabelecer a interação entre Universidade e Sociedade. Por sua indefinição e falta de regulação, agrega todas as iniciativas que não se encaixam em Ensino ou Pesquisa. Encontram-se, de um lado, empresas juniores, cursos pagos e fundações de apoio, e, de outro, projetos de extensão com raro apoio institucional ou mesmo docente, mas que pautam uma universidade que confira valor social ao conhecimento produzido.

No debate acerca do que é extensão, então, o projeto Educar Para o Mundo encontra-se na última visão acima descrita, compreendendo que a real práxis extensionista é aquela que, calcada na pedagogia freiriana, estabelece um diálogo horizontal com seus interlocutores (Freire, 1971, p. 1994), buscando não só a troca de conhecimento entre o que se produz dentro dos muros da universidade e os conhecimentos produzidos fora deles, mas também a emancipação dos sujeitos sociais que participam do fazer extensionista.

Por meio da análise das atividades realizadas pelo projeto, o presente artigo pretende discutir as possibilidades e os limites proporcionados pela extensão universitária para transformar e complementar o saber acadêmico, bem como para transformar a realidade com a qual o projeto comprometeu-se, de início, a trabalhar: a realidade dos direitos humanos dos migrantes latino-americanos em São Paulo, mais especificamente em uma escola municipal no Canindé, bairro central da cidade.

A prática extensionista nos fez perceber, enquanto estudantes de Relações Internacionais e acadêmicos, que para a compreensão do fenômeno migratório e da busca pela maior proteção dos direitos humanos desses atores, era necessário conhecer e conectar uma rede complexa de fenômenos sociais, entre eles: as relações de trabalho presentes no setor têxtil em São Paulo (Freire da Silva, 2009), as legislações brasileiras acerca do estrangeiro, bem como os problemas educacionais do país, mais 
especificamente o lugar dos direitos humanos no ambiente escolar (Benevides, 2004).

Dessa forma, a proposta dialógica do projeto mostrou ser necessária a articulação entre os diversos atores, âmbitos e temas para que o projeto se realizasse. Portanto, atualmente, o projeto Educar Para o Mundo, a fim de dar maior consistência às suas atividades, faz-se presente em diferentes campos de ação. Entre eles, desenvolve atividades em parceria com a Escola Municipal Infante Dom Henrique, articula atividades com associações e movimentos de imigrantes, principalmente em busca de mudanças de legislação e efetivação de políticas públicas dos governos municipal, estadual e federal, além de se inserir na luta pela transformação das estruturas da própria universidade e da visão sobre sua função social, em parceria com outros projetos de extensão, formando o Fórum de Extensão da USP.

Tais descobertas proporcionadas pela prática extensionista nos apresentaram, então, a uma nova maneira de estudar as migrações e os direitos humanos, bem como de desenvolver as atividades do projeto. Passamos, inclusive, aos poucos, a compreender a limitação do conceito de direitos humanos que possuímos no mundo acadêmico, acrescentando a eles as visões dos nossos interlocutores, estimuladas pelas suas realidades. Além disso, foi possível constatar lacunas entre o que nos propusemos e o que de fato ocorreu com o passar o tempo. A prática da extensão popular traz em si algumas limitações e contradições, as quais sempre buscamos superar em um processo infinito de pensar e repensar o projeto. Portanto, torna-se necessário discutir acerca dos problemas enfrentados pelo Projeto a fim de que possamos contribuir para a construção da práxis extensionista.

Assim, a partir dessas realidades e ao pautar o diálogo, a horizontalidade e a criticidade, o Projeto Educar Para o Mundo entende que a produção do conhecimento na Universidade deve servir para a transformação social e a superação das opressões; contribuir para democratizar o ambiente acadêmico e a sua produção; e proporcionar uma nova maneira de 
|144|

Educar para o Mundo...

entender processos importantes das relações internacionais contemporâneas.

\section{A práxis do projeto: descrição das atividades}

\section{A escola}

As atividades do projeto se iniciaram em 2009, em parceria com a Escola Municipal Infante Dom Henrique, localizada no bairro do Canindé, em São Paulo, na qual cerca de 10\% do corpo discente é imigrante. Primeiramente, buscou-se a aproximação com o corpo docente e a coordenação da escola por meio de reuniões no espaço das JEIFs (Jornada Especial Integral de Formação) e da discussão gerada a partir da exibição do filme francês "Entre os Muros da Escola", de Laurent Cantet. Tal momento propiciou reflexões sobre problemas enfrentados diariamente nas escolas públicas, inclusive aquelas com grande quantidade de alunos imigrantes.

Já no segundo semestre, iniciou-se a realização de oficinas, em encontros quinzenais com os alunos da escola, as quais proporcionaram uma atividade mais livre de troca de saberes, sendo um espaço sem hierarquias, com menor formalidade e em que todos possuíam a mesma possibilidade de intervenção. Tais oficinas abordaram temas de relevância para a educação popular dos Direitos Humanos a partir da arte e do mundo da cultura, facilitando, assim, a aproximação do tema com o indivíduo.

A Oficina de Grafite foi pensada para tentar romper o cinza da cidade e do cotidiano e para introduzir a questão do espaço público e a necessidade de ocupá-lo, de nos sentirmos parte dele. Tendo o muro da escola como suporte, desmistificou-se o "fazer arte" ao torná-lo acessível a qualquer pessoa. Ao retratar violações cotidianas aos direitos humanos, o grafite é, em si mesmo, o exercício do direito fundamental da liberdade de expressão.

Outra oficina, denominada "Quadrinhos", possibilitou a discussão concreta acerca da Declaração dos Direitos da Criança da Organização das Nações Unidas (ONU) de 1959, bem como a 
reflexão sobre os problemas da convivência e da discriminação na escola e em outros ambientes, que geram violações desses direitos. Isso foi abordado pelos alunos através de histórias em quadrinhos digitais que eles confeccionaram e que depois se transformaram em animações.

De outro lado, a oficina de fotografia trouxe a questão da preservação da identidade com o tema "Auto Retrato". Os alunos confeccionaram máquinas fotográficas pinhole a partir de caixas de papelão, tintas e papel fotográfico, e registraram momentos individuais e em grupo, que, depois de por eles revelados no laboratório montado na escola, suscitaram o debate a respeito de suas autoimagens e da percepção de pertencimento e de identidade dos grupos.

No ano de 2010, o projeto promoveu, no primeiro semestre, três oficinas com o objetivo de discutir espaço público, educação pública e direitos humanos. Na primeira, a participação de estudantes do Cursinho Comunitário Pimentas permitiu a problematização das questões do acesso à educação pública e os problemas que os alunos enfrentavam em sua própria escola.

Na segunda oficina, cerca de 40 alunos da escola fizeram uma visita à Universidade de São Paulo (USP), a partir da qual, além de conhecerem os espaços da universidade, discutiram o espaço público e sua relação com ele. Colocou-se a questão de que espaços como a USP, a escola onde eles estudam ou as praças da região da escola são públicos, mas que não são apropriados pela comunidade, a qual não os compreende enquanto verdadeiramente públicos. Na terceira e última oficina do semestre, os alunos, reunidos na escola Infante Dom Henrique, apresentaram as fotografias que eles produziram durante a visita à USP e fizeram uma reflexão sobre as oficinas anteriores, retomando pontos centrais de suas discussões de maneira a buscar uma maior consolidação desses temas.

Já no segundo semestre, a tentativa foi de realizar uma atividade com os alunos do grêmio da escola em conjunto com os frequentadores da feira latino-americana que ocorre todos 
|146|

Educar para o Mundo...

os domingos na Praça Kantuta, também localizada no bairro do Canindé, em pareceria com o Centro de Apoio ao Migrante (CAMI) e a Associação Kantuta. Realizou-se uma intervenção de grafite na praça a fim de transformar seus muros brancos em uma real e simbólica apropriação desse espaço público.

No ano de 2011, o projeto passou a elaborar em conjunto com a escola o novo Projeto Político Pedagógico da instituição, o qual traria para o centro da escola o tema da diversidade, matriz comum entre os assuntos abordados pelo projeto, e a nova perspectiva da direção da escola acerca dos problemas enfrentados por ela.

Assim, com a participação do Educar Para o Mundo nesse novo contexto da escola, pensou-se na elaboração de um ciclo de formação da comunidade escolar, em conjunto com os próprios professores, a partir de temas geradores, bem como em um projeto de confecção de uma cartilha de Direitos Humanos pelos alunos dos Ciclos 1 e 2.

Para iniciar o ciclo de formação, no contexto da concepção freiriana de extensão comunicativa, escolheu-se o Círculo de Cultura, que se mostra mais que um mero instrumento metodológico para a relação com o interlocutor social. O Círculo de Cultura representa uma opção política pelo aprofundamento da consciência crítica de todos os sujeitos envolvidos na transformação da realidade, estabelecendo relações horizontais mediadas pelo diálogo. Com base nesse pressuposto, acordou-se com os professores que seriam feitos dois Círculos de Cultura no final de julho, tendo em vista a construção dos temas a serem tratados no curso de formação em Educação para os Direitos Humanos que se pretende estruturar. Assim, como resultados dos Círculos, foram escolhidos dois temas centrais sobre os quais as atividades do curso de formação deveriam tratar: A questão da identidade, e Cidadania e direito à educação.

Em relação à cartilha de Direitos Humanos, trata-se de um projeto elaborado pelo Educar Para o Mundo voltado para os alunos e professores da escola. Pretende-se, a partir de cinco direitos humanos (direito à identidade, à educação, à mobilidade, 
ao lazer e à organização), estimular o interesse e o envolvimento tanto do corpo docente como do corpo discente para com o tema, a partir da reflexão, cooperação e respeito em grupo. Para tal, foram pensadas diferentes atividades lúdicas, nas quais os alunos são estimulados a vivenciar cada um desses direitos e significá-los a partir das suas próprias experiências. Essas diferentes visões sobre cada direito serão compiladas na Cartilha de Direitos Humanos, que se pretende um modelo para se trabalhar a questão dos direitos humanos dentro do ambiente escolar.

\section{A articulação política externa: os movimentos de migrantes}

O Educar Para o Mundo consolidou, no ano de 2009, sua atuação mais ampla com movimentos e organizações de imigrantes, uma vez que entende necessária para a práxis extensionista a relação com grupos politicamente organizados dentro da comunidade. Tal relação não só permite ampliar o rompimento dos muros da universidade, trazendo para dentro dela as demandas e disputas políticas e sociais dos interlocutores, como também possibilita que a própria instituição participe das disputas e reivindique essas demandas.

Primeiramente, elaborou-se o seminário Estatuto do Estrangeiro, em parceria com o Centro de Apoio ao Migrante (CAMI), o qual ocorreu em 2009 na Faculdade de Direito da USP, trazendo a discussão acerca da atual lei do estrangeiro e sua proposta de reformulação. Durante o seminário, que contou com o apoio e participação de diversas organizações e entidades governamentais, estudantes, migrantes, acadêmicos de diferentes áreas do Brasil e de outros países, defensores públicos e outros profissionais da área do Direito, o novo projeto de lei (PL) foi discutido intensamente. Grupos de trabalho relataram as discussões discriminando os déficits, incoerências e algumas vezes a inconstitucionalidade de cada artigo do PL. A troca de experiências e conhecimentos foi intensa: em uma mesma sala, migrantes compartilhavam sua vivência prática, materialização 
e implicações daquela legislação, enquanto juristas traziam arcabouço técnico.

No segundo semestre de 2010, passamos a ser uma das entidades organizadoras do Fórum Social de São Paulo (FSSP), um processo de articulação de organizações e movimentos sociais da região metropolitana de São Paulo inspirado no Fórum Social Mundial. Dentro desse processo, o Educar Para o Mundo promoveu duas atividades autogestionadas do FSSP no ano de 2010: uma intervenção de grafite na Praça Kantuta em parceria com o grêmio estudantil da escola Infante Dom Henrique e um seminário sobre "Fronteiras do Direito à Educação: os imigrantes bolivianos nas escolas públicas de São Paulo", com a participação de Giovanna Modé Magalhães, mestra em educação pela Faculdade de Educação da USP.

Ademais, a realização do debate "Os migrantes e a indústria de confecções em São Paulo", que contou com a contribuição do sociólogo Carlos Freire da Silva, pautou o histórico e a atual situação do trabalho dos bolivianos na indústria de confecções em São Paulo. Discutiu-se que, no decorrer dos anos 90, com o crescimento do mercado de trabalho informal, imigrantes irregulares foram atraídos para trabalhos mal remunerados e sem rigor quanto às restrições trabalhistas. A intensificação do fluxo de imigrantes bolivianos para São Paulo, diretamente ligado às transformações do circuito das confecções e ao crescimento industrial durante o "milagre econômico", tornou-os o maior grupo de imigrantes latinos da cidade após passar por diferentes etapas (Freire da Silva, 2009).

Outro evento realizado em 2011 pelo Educar Para o Mundo foi o seminário "Política brasileira para as migrações: interesse nacional vs. Direitos Humanos", no qual Jobana Moya, representante da sociedade civil, grupo das mulheres, debateu com Paulo Sérgio de Almeida, presidente do Conselho Nacional de Imigração, as opiniões dos membros de diferentes setores envolvidos na questão dos imigrantes no Brasil, especialmente em relação à dificuldade da obtenção de documentos para cidadãos internacionais que chegam a nosso país. 
Para além destes, o Educar Para o Mundo esteve presente em importantes eventos no Brasil e no mundo, buscando uma articulação mais ampla desses assuntos. Por exemplo, participou do X Congreso Iberoamericano de Extensión Universitária (Montevideo, Uruguai), do XII Fórum de Estudos: Leituras de Paulo Freire (Porto Alegre, RS), onde apresentamos um artigo escrito pelo projeto; do Seminário Horizontes - Movimentos sociais e direitos humanos (Curitiba, PR); do Seminário Proext do Ministério da Cultura (São Paulo, SP); do Fórum Paulista de Extensão (São Carlos, SP); do Fórum Social Mundial das Migrações (Quito, Equador); e da Cúpula Social do Mercosul (Foz do Iguaçu, PR).

\section{Articulação política interna: o Fórum de Extensão da USP}

Romper com a barreira posta pela nossa formação especializada e dialogar com estudantes de diferentes campos do conhecimento é fundamental para uma extensão universitária que esteja dialogando com a realidade, já que a própria realidade não aparece em compartimentos de especialidades, mas sim em totalidades. O Fórum de Extensão da USP é um espaço em que diferentes núcleos de extensão se organizam dentro da universidade.

Além disso, para defender uma concepção comunicativa, freiriana, da extensão universitária, entende-se que é necessária uma organização política capaz de disputar o próprio conceito de extensão dentro da Universidade de São Paulo. A universidade ainda é um espaço restrito perante a burocracia universitária, professores, funcionários e alunos.

O grupo se reúne desde 2009 e promove diversos debates entre os próprios núcleos de extensão e entre os demais estudantes da USP. A última atuação do Fórum de Extensão ocorreu na Semana de Recepção dos Calouros de 2011 com a constituição da oficina "A Universidade e a produção de conhecimento". Questionou-se o chamado conhecimento científico, comparando-o com outras maneiras de se produzir 
|150|

Educar para o Mundo...

conhecimento. Com o intuito de, ao mesmo tempo, divulgar a extensão universitária, a atividade problematizava um dos maiores pressupostos sobre a universidade, qual seja, a de que ela é a autoridade de um conhecimento neutro, correto e superior.

Atividades como essa, somadas aos encontros periódicos do Fórum de Extensão da USP, mostram as dificuldades do fazer extensão, ao mesmo tempo em que permitem vislumbrar possíveis soluções. Da mesma maneira, torna-se cada vez mais clara a necessidade de mudanças na estrutura universitária, que somente serão possíveis quando estivermos organizados, também como grupos de extensão, colocando-nos como agentes políticos dessa transformação.

\section{Olhando para trás: uma reflexão sobre o percurso}

Uma avaliação superficial do nosso projeto poderia concluir que ele foi extremamente bem sucedido no que tange a quantidade e abrangência das atividades realizadas. Em três anos de um projeto composto em sua maioria por estudantes de graduação, trabalhando voluntariamente, com recursos escassos e tempo disponível limitado, conseguimos conquistas substanciais para um projeto de extensão da USP. Para citar algumas delas: inserção e aceitação dentro de uma comunidade que nos era totalmente estranha, organização de debates visando pautar políticas públicas de imigração em nível federal, grandes intervenções artísticas com participação popular, participação em diversos congressos e eventos nacionais e internacionais, sem contar trazer para dentro da Universidade de São Paulo a discussão sobre as correntes migratórias recentes do país.

No entanto, se olhamos para os objetivos do projeto definidos em 2009 - e para a concepção de extensão e de pesquisaação que julgamos adotar, veremos que nos desviamos da rota planejada, ou ao menos que nosso percurso foi mais tortuoso do que deveria ter sido. Seja por despreparo e falta de organização do grupo, seja pelas condições que enfrentamos no campo, nossas propostas iniciais (ainda, quiçá) não vingaram por completo. 
Partindo dessa constatação serão expostos a seguir os objetivos iniciais do Educar para o Mundo. Comparando-os com a concepção de extensão que o grupo adotou, faremos um diagnóstico do que faltou para atingir de fato nossas expectativas. Na nossa visão os motivos do "sucesso incompleto" do projeto pois como já afirmamos, muito foi feito - estão relacionados a três fatores principais: as deficiências na organização interna do grupo; os obstáculos encontrados na escola Infante Dom Henrique; e a insuficiente aproximação com os movimentos sociais organizados.

\section{Os objetivos e a extensão que queremos}

Os objetivos gerais e específicos do Educar para o Mundo enviados à Pró-Reitoria de Cultura e Extensão da USP no ato da inscrição no programa "Aprender com Cultura e Extensão" do período 2009/2010 são os seguintes:

\section{Gerais}

a) Qualificar a formação do graduando em Relações Internacionais, tornando-o apto para atuação de campo, desenvolvendo seu senso crítico, e outorgando densidade prática à sua concepção de direitos humanos;

b) Contribuir à educação para os direitos humanos, numa relação dialógica com a comunidade-alvo, tendo em perspectiva tanto a melhoria da qualidade de vida dos beneficiários como a consecução da função social da universidade pública;

c) Desenvolver paulatinamente uma metodologia extensionista própria à área de Relações Internacionais, diferenciando-se das atividades práticas profissionais (tais como simulações) e contribuindo para a incorporação ao exercício da cidadania de elementos complexos, como a compreensão dos fenômenos internacionais e de sua tradução no cotidiano da população brasileira;

d) Estimular na comunidade-alvo e nos universitários envolvidos as competências necessárias à atuação em projetos de 
cooperação internacional relativos à efetividade dos direitos humanos.

\section{Específicos}

a) Contribuir à organização de atividades de formação dos docentes da escola-alvo para tratamento de temas internacionais e de direitos humanos em sala de aula, com o apoio dos quadros da ANDHEP';

b) Participar da organização de atividades culturais da escola-alvo, envolvendo pais, alunos, professores, funcionários e lideranças comunitárias;

c) Estimular e prestar assessoria técnica à concepção de iniciativas para gestão da alteridade, além do combate à violência derivada da xenofobia, particularmente por meio da elaboração de projetos vinculados à efetividade dos direitos humanos e captação de recursos internacionais para sua implementação;

d) Aliar à atividade extensionista atividades de ensino e pesquisa, em especial por meio da criação de um grupo de estudos vinculado ao projeto, e de atividades de autoformação para campo, tanto básica como contínua, com o apoio da ANDHEP.

Com relação à extensão que adotamos, já foi dito na introdução deste artigo que ela se caracteriza por uma relação horizontal entre o saber acadêmico e popular, que busca estabelecer um diálogo democrático com nossos interlocutores com vistas não só a trocar conhecimentos entre universidade e sociedade, mas também contribuir para a emancipação das classes oprimidas. Em suma, nossa concepção bebe direto da fonte da teoria pedagógica e política freiriana.

Intimamente relacionada a essa perspectiva extensionista está a pesquisa participante, ou pesquisa-ação. Tal abordagem metodológica surge para colocar em xeque a postura do pesquisador neutro, desinteressado, que busca a legitimidade

\footnotetext{
${ }^{1}$ Associação Nacional de Direitos Humanos - Pesquisa e Pós Graduação, na qual contamos com colaboradores.
} 
do saber científico congelando a realidade social e transformando os indivíduos em objetos estáticos para serem dissecados, examinados e classificados. Coloca o arquétipo do pesquisador positivista quando este se pergunta: para que serve este conhecimento que minha ciência acumula? A quem ele interessa? Em nome de quê estou fazendo isso (Brandão, 1981, p. 10)? Se toda a ciência é interessada, serve a alguém - ainda que nem os próprios cientistas o saibam - que seja do interesse das "classesobjeto" no sentido de sua emancipação. Que seja feita direcionada a ela, realizada junto a ela, e que retorne a ela.

Um caminho possível da pesquisa participante, que nutre e se alimenta da prática extensionista ao ponto de ser muito difícil dissociá-las, obedece às seguintes quatro etapas: "processo de inserção do pesquisador no campo, coleta da temática geradora do grupo com quem se trabalha, organização do material recolhido junto ao povo e devolução sistemática para discussão e debate" (Oliveira e Oliveira, 1981, p. 27). Assim, o projeto científico de pesquisa deveria ficar subordinado ao projeto político dos grupos populares (Brandão, 1981, p. 12).

Ainda que Brandão reconheça que, no que tange à pesquisa participante, "há muito mais experiências em processo do que teorias consagradas", são estas as diretrizes que tentamos aplicar no Educar para o Mundo. A partir delas é que faremos nossa autocrítica.

\section{Os objetivos e a extensão que fizemos}

Faz parte de um projeto de extensão dito dialógico que os objetivos iniciais mudem de acordo com as exigências da prática². Não queremos condenar o projeto por não ter seguido à letra um documento gestado por alguns integrantes, e sim usar os objetivos como marcos de comparação.

2 "Os objetivos da prática não podem estar de maneira nenhuma esquecidos nem separados das maneiras como se faz a prática." (Freire, 1982). 
|154|

Educar para o Mundo...

É fácil falar do que deu certo: conseguimos com muito sucesso desenvolver o senso crítico dos integrantes do projeto e evoluímos muito em nossa atuação no campo, o que jamais teríamos conseguido ficando na sala de aula. Além disso, organizamos atividades culturais na escola-alvo e de formação dos docentes, estimulamos o combate à xenofobia e fizemos diversos estudos e formações na universidade sobre os temas que perpassam o universo do projeto (direitos humanos, imigração, exploração do trabalho etc.), trazendo a experiência adquirida em campo.

O que dizer, no entanto, sobre os pormenores que dão sentido crítico e emancipatório ao projeto? Conseguimos desenvolver uma metodologia extensionista própria, sólida, em relações internacionais? Os docentes da escola-alvo passaram a discutir direitos humanos com seus alunos em sala de aula? Engajamos com sucesso alunos, professores, pais e funcionários na luta pelos direitos humanos e no combate à discriminação contra os imigrantes? Eles estão habilitados a desenvolver projetos por si próprios neste sentido, buscando inclusive apoio de organizações internacionais?

Mais importante: estabelecemos, com a escola e com os diversos atores da comunidade a que tivemos acesso, uma relação horizontal, dialógica e emancipatória? Só até certo ponto.

Nosso diagnóstico é que estacionamos na primeira etapa da pesquisa participante, a da inserção do grupo no campo. Hoje nosso nome é conhecido por diversos atores da sociedade civil, do governo e da universidade. Estamos credenciados a trabalhar com a escola e com os imigrantes.

Quanto às outras etapas, chegamos a elas em certos momentos e de forma ainda pontual. Em algumas atividades coletamos os temas geradores junto aos interlocutores (e.g., oficina de animação e formação dos professores), em outras chegamos a organizar o material coletado (e.g.: discussões sobre espaço público em 2010). No entanto ainda não fomos bem sucedidos em percorrer as quatro etapas de uma pesquisa participante, calcados numa relação de diálogo democrático com nossos 
interlocutores. A única exceção é a cartilha de direitos humanos iniciada em 2011, da qual trataremos mais adiante.

Vemos três motivos para o já mencionado sucesso incompleto do Educar para o Mundo: organização interna, obstáculos da escola Inf. D. Henrique, aproximação insuficiente com atores sociais.

\section{Organização interna}

O coletivo do Educar para o Mundo é organizado por autogestão. Não há hierarquias entre os membros e nossa coordenadora tem tanta voz nos rumos do projeto quanto qualquer outro integrante. As decisões são tomadas em plenárias semanais, onde também são formadas as comissões executivas para realizar as atividades propostas ${ }^{3}$. Reiterando: somos um grupo de estudantes de graduação que não recebe qualquer ajuda de custo para estar no projeto. A dedicação à extensão fica espremida entre aulas e estágios, provas e trabalhos. Essa é a realidade da maioria dos extensionistas na Universidade de São Paulo, cujo apoio à extensão universitária é talvez um dos mais limitados do país entre as universidades públicas.

Se no começo queríamos trazer os interlocutores do projeto para participar de nossas plenárias de formação e planejamento iniciais, alargando nossa abertura a eles, logo percebemos as dificuldades de se operacionalizar isso. Tendo nós mesmos tão pouco tempo disponível, a flexibilidade de horários era quase inexistente para atender às agendas de pessoas externas à universidade, que não só estavam distantes de nós, como tinham

\footnotetext{
${ }^{3}$ Vale ressaltar que o processo para se chegar a esse formato foi longo. Pecamos muitas vezes pela falta de organização do grupo, que tentava a todo custo fazer o modelo de autogestão democrática funcionar. Quando superamos tanto a ultra romantização da autogestão como a recusa da burocratização, encontramos um meio termo funcional. Este modelo sempre foi uma das nossas principais bandeiras e, hoje, uma de nossas maiores conquistas.
} 
|156 |

Educar para o Mundo...

outro "tempo" (trabalhavam ou estudavam o dia inteiro, cuidavam da família etc.). Ficou assim prejudicada a segunda etapa da pesquisa participante, da coleta dos temas geradores junto a nossos parceiros.

Essa distância e escassez de tempo foi um entrave crucial em nossas relações com a escola Inf. D. Henrique. Era difícil estar na escola nos horários de funcionamento e estava fora de cogitação trazer os professores para a USP, o que dificultou muito o diálogo com eles. Em outras palavras, nossas capacidades não estavam a par do desafio que seria lidar com a escola.

\section{Obstáculos da escola}

Foi no trabalho com a escola municipal Inf. D. Henrique que mais erramos, e foi também onde mais aprendemos. Cabe discorrer antes sobre como foi nossa entrada na escola, os problemas que ela - assim como a maioria das escolas públicas brasileiras - enfrenta, e por fim lançar nosso diagnóstico.

Para começo, a escolha desta escola foi arbitrária. A Inf. D. Henrique atendia dois dos nossos requisitos: se localizava na região de interesse (bairro Bom Retiro/Canindé) e tinha um número expressivo de alunos imigrantes. Contudo, no afã de iniciar o projeto, escolhemo-la por ser a primeira escola que nos acolheu, sem antes realizar um estudo maior das escolas da região, nos informar sobre projetos prévios e conversar com lideranças sobre aquela comunidade, como seria recomendável (Oliveira e Oliveira, 1981, p. 38). Fomos muito bem recebidos e logo começamos a ter reuniões com os professores.

Na primeira reunião entre equipe e professores, tivemos uma amostra do que enfrentaríamos pela frente. Alguns professores estavam entusiasmados com nossa chegada, a maioria parecia incomodada ou indiferente. Fora a perspectiva deles sobre a questão dos imigrantes na escola, o que de mais interessante surgiu foram comentários como "esperávamos que vocês fossem trazer uma fórmula mágica para resolver os problemas da escola", ou "iremos receber certificados da USP por isso?". Ou seja, logo 
de saída sentimos a visão que a sociedade tem da universidade e de seus projetos de extensão, carregada de messianismo, mecanicismo e superioridade por parte de quem estende (Freire, 1977). Espera-se, a priori, que sejamos solucionadores de problemas, e não que pensemos e atuemos juntos para construir soluções.

Contudo foi outro comentário desta reunião que ilustrou com clareza explícita a crise que essa e tantas outras escolas vivem. Uma professora, ao comentar dos alunos bolivianos e comparar seu comportamento com o dos brasileiros, afirmou sem hesitar: na Bolívia os professores eram respeitados porque podiam bater nas crianças.

"A escola não serve para nada socialmente", "a sensação no Brasil é de que o professor está sozinho, sem apoio, sem instrumentos de coerção e, portanto, sem autoridade", "é preciso levantar a autoestima dos estudantes, que estão desmotivados". Todos esses são trechos de comentários dos professores. E eles se encaixam como uma luva na análise de Regina Magalhães de Souza sobre a escola contemporânea, de que a crise na escola faz parte da crise de autoridade do mundo moderno (Souza, 2003).

A autora concorda com a filósofa Hannah Arendt em seu diagnóstico da crise de autoridade no mundo moderno. Souza afirma que tal crise, em que os adultos e educadores "não querem se responsabilizar pelo curso das coisas" (Souza, p. 26), provoca um esvaziamento das funções tradicionais. Na escola ela se traduz como ausência de projeto conciso de educação. Sem finalidade educativa, a regulação da organização escolar se torna a única função que a mantém de pé, agarrando-se a "regras e procedimentos arbitrários e inconstantes" (Souza, p. 42). Sem finalidade o professor perde autoridade e o magistério se torna profissão desprestigiada. Cai o professor, dessa forma, na afirmação de Brandão: educação vira sistema e o educador mero fiscal do ensino (Brandão, 1982, p. 77).

Em um contexto no qual a educação está dividida entre confrarias de especialistas e técnicos que não têm nenhum contato 
|158|

Educar para o Mundo...

com a prática cotidiana, e os educadores estão preocupados com o acúmulo imenso de tarefas repetitivas e o escasso salário no fim do mês (Brandão, p. 79), em que os "fiscais do ensino" estão compromissados quase somente com o conteúdo da sua disciplina e despreparados para lidar com a diversidade em sala de aula, em que os jovens estão "invisíveis" (Freitas, 2007), quais os limites da atuação de um projeto de extensão organizado como descrevemos acima?

Esbarramos em um interlocutor destituído de sentido pela crise da escola moderna (ou da escola pública brasileira). As atividades que apontamos no início do artigo aconteceram, mas nunca conseguimos estabelecer um diálogo horizontal sólido e duradouro com os professores. Nossos esforços eram recebidos com indiferença, protestos e algumas vezes com má vontade. Não tínhamos tempo disponível, recursos suficientes e preparação adequada para enfrentar tamanho desafio, o que frustrou bastante vários integrantes da equipe. Se nosso projeto deu certo até agora foi por conta principalmente dos alunos do colégio.

As intervenções artísticas que organizamos, as discussões sobre direitos humanos e imigração, oficinas sobre racismo, espaço público, identidade, grafitagem, aconteceram por acolhimento dos alunos. Nossa atividade mais promissora, a cartilha dos direitos humanos, foi feita em colaboração direta com eles, e foi a que chegou mais próximo da extensão que queremos. Não é surpresa. A dimensão socializadora da escola se sustenta hoje na capacidade do próprio aluno de se movimentar dentro do sistema (Souza, 2003, p. 43). A relação entre equipe e alunos só não foi mais profícua porque eles não estavam politicamente organizados. O grêmio estudantil era demasiado fraco e por isso nossa comunicação tinha que ser mediada pelos professores.

Para além de todos os erros, frustrações e acertos em nosso trabalho na Inf. D. Henrique, aprendemos na prática que a extensão universitária não consegue se sustentar sem a contrapartida do interlocutor, da comunidade, do ator social. É tendo isso em mente que o Educar para o Mundo deve trabalhar 
no futuro, seja com escolas seja com movimentos sociais organizados.

\section{Os movimentos organizados}

Em relação aos movimentos, há pouco a dizer, porque pouco foi tentado. Nossa relação com os movimentos de imigrantes, em geral, ficou na primeira etapa da inserção. Somos conhecidos pelos atores, mas nunca propusemos trabalhos de base concretos junto com eles.

Nossos principais interlocutores neste grupo são o Centro de Apoio ao Migrante (CAMI) e a Associação Cultural da Kantuta, que organiza a feira dominical dos imigrantes no centro. Através deles realizamos diversas atividades e eventos, como a intervenção artística na praça e os debates sobre o Estatuto do Estrangeiro que tramita no Congresso atualmente. Apesar da nossa relação próxima, ainda não foram pensadas ações conjuntas que envolvessem equipe do projeto e estas organizações. Temos que considerar ainda a imensa gama de organizações de imigrantes que existem na cidade de São Paulo, desde associações de trabalhadores da costura até grupos culturais que mantêm vivas as tradições nacionais da Bolívia no coração da capital paulista. Todos são parceiros em potencial, com projetos sólidos com os quais poderíamos dialogar. Pouco foi tentado porque ainda estávamos "presos" à escola.

A lição que aprendemos na escola deve ser aplicada a este grupo. Movimentos possuem em geral agendas e objetivos concretos, com os quais se pode estabelecer uma relação horizontal, crítica, dentro das concepções extensionistas em que acreditamos.

\section{Conclusão}

Este artigo buscou resumir todas as atividades em três anos de um projeto de extensão pioneiro, que se propõe a desenvolver extensão dialógica na área de relações internacionais. Além disso, 
$|160|$

Educar para o Mundo...

expusemos uma autocrítica, fruto da reflexão coletiva do grupo, do nosso percurso.

A conclusão que fica é que a extensão, enquanto via de mão dupla entre atores sociais e universidade, não pode prescindir da pesquisa participante. Somente assim a práxis freiriana, ou seja, a teoria unida à prática, será plenamente realizada. Não podemos nunca esquecer que somos cientistas em uma universidade pública, cuja função principal é a produção de conhecimento. Nossa especificidade é que cremos que este conhecimento deve ser socialmente relevante, direcionado à correção das injustiças da sociedade e construído em conjunto com seus atores.

Dessa forma, faz-se fundamental que tenhamos interlocutores organizados ativos, e não indivíduos passivos esperando por soluções prontas. Este é o limite de um projeto de extensão. Ele só se realiza plenamente quando há alguém no alémmuros disposto a dialogar. Prova disso foi nosso insucesso com os professores da escola, por diversos motivos (alguns que escapam do nosso escopo, i.e. crise da escola moderna), e a promissora construção da cartilha junto aos alunos. Ela agora está em processo de sistematização e retornará aos alunos para que seja utilizada nesta e em outras escolas.

Por fim, tudo que fizemos não foi de forma alguma em vão. As atividades, debates, congressos, intervenções, palestras e oficinas serviram muito bem a seus propósitos e hoje temos uma visão muito mais profunda de direitos humanos e imigração do que a sala de aula poderia nos proporcionar. Contudo elas não podem ser nosso fim último, pois sem concretizar o diálogo democrático que tanto pregamos essas ações serão sempre pontuais, assistencialistas, e nunca extensão freiriana.

\section{Bibliografia}

BENEVIDES, M. V. "Educação para a democracia". Lua Nova. Revista de Cultura e Política, São Paulo, v. 38, p. 223-237, 2004. 
BRANDÃO, C. R. "Pesquisar-participar". In: BRANDÃO, Carlos R. (org.). Pesquisa Participante. 8 $8^{\underline{a}}$ ed. São Paulo: Brasiliense, 1981, p. 9-17. 1984.

Repensando a Pesquisa Participante. São Paulo: Brasiliense,

"Refletir, discutir, propor: as dimensões de militância intelectual que há no educador". In: BRANDÃO, C. R. (org.) O educador: vida e morte. São Paulo: Graal, 1982, p. 71-89.

BRASIL. Projeto de Lei 5655/2009. Disponível em: $<$ http://www.camara.gov.br/proposicoesWeb/ fichadetramitacao?idProposicao=443102>. Acesso em: 08 ago. 2011.

CANDAU, V. M. "Direitos Humanos, Educação e Interculturalidade: as tensões entre igualdade e diferença". Revista Brasileira de Educação, Rio de Janeiro, v. 13, n. 37, 2008.

DINIZ, R. A. F. C. Construindo o projeto político pedagógico dialógico. 2008. Disponível em: <http://www.webartigos.com/articles/ 12278/1/Projeto-Politico-Pedagogico/pagina1.html>. Acesso em: 08 ago. 2011.

FREIRE DA SILVA, C. "Precisa-se: bolivianos na indústria de confecção de São Paulo". Travessia. Jan./abr. 2009.

FREIRE, P. Extensão ou comunicação? $10^{\underline{a}}$ ed. Rio de Janeiro: Paz e Terra, 1977.

Pedagogia do oprimido. Rio de Janeiro: Paz e Terra, 1994.

"Educar. O sonho possível". In: BRANDÃO, Carlos R. (org.) O educador: vida e morte. São Paulo: Graal, 1982, p. 89-103.

FREITAS, M. V. "A invisibilidade da juventude no PDE". Correio Brasiliense, Caderno Gabarito, Brasília, 28/10/2007. Disponível em: <http://www.observatoriodaeducacao.org.br/ index.php?option=com_content\&view $=$ article\&id $=403$ :a- 
$|162|$

Educar para o Mundo..

invisibilidade-da-juventude\&catid=57:artigos\&Itemid=37> . Acesso em: 20 mar. 2012.

MAGALHÃES, G. M. Fronteiras do direito humano à educação: um estudo sobre os imigrantes bolivianos nas escolas públicas de São Paulo. 2010. Dissertação (Mestrado) - Universidade de São Paulo, Faculdade de Educação, São Paulo.

OLIVEIRA, R.; OLIVEIRA, M. "Pesquisa Social e ação educativa: conhecer a realidade para poder transformá-la". In: BRANDÃO, C. R. (org.). Pesquisa Participante. $8^{\underline{a}}$ ed. São Paulo: Brasiliense, 1981, p. 17-34.

SOUZA, R. M. Escola e Juventude: o aprender a aprender. São Paulo: EDUC/Paulus, 2003.

TOMASEVISKY, K. T. Observações gerais, Comitê DESC, n.13, 1999. 